RUNNING HEAD: THE IAT AND SOURCE ATTRACTIVENESS AND LIKEABILITY

The impact of persuasive messages on IAT performance is moderated by source attractiveness and likeability

In Press. Social Psychology.

Word count: 7460 


\begin{abstract}
In two studies, participants read persuasive messages introduced by an attractive (Study 1) or likeable (Study 2) source before completing measures of implicit and explicit evaluations. The persuasive messages were in favor of an unfamiliar brand of facial soap (Study 1) and the implementation of comprehensive examinations at the participants’ university (Study 2). Results showed that persuasive messages had a stronger impact on an Implicit Association Test when the source was high in attractiveness or likeability (Study 1 and Study 2); responses on an Affect Misattribution Procedure, though in the predicted direction, were not significantly impacted by a source high in likeability (Study 2). These findings parallel those of numerous studies that, however, have looked almost exclusively at persuasion of explicit evaluations. They confirm that implicit evaluations can be changed through direct persuasive appeals and provide new information about the conditions under which persuasion of implicit evaluations can be found.
\end{abstract}

Word count: 150 


\section{The impact of persuasive messages on IAT performance is moderated by source attractiveness and likeability}

It has now been more than half a century since persuasion researchers began separating the effects of source factors from message and audience factors (e.g., Hovland, Janis, \& Kelley, 1953). In the intervening years, our ability to fine-tune persuasion based on these factors (among others) has increased greatly - spurred in large part by the theoretical advances of the Elaboration Likelihood Model (Petty \& Cacioppo, 1986) and the Heuristic Systematic Model (Chaiken, 1980). These three related approaches have formed the bedrock of how modern social psychologists understand persuasion to occur.

Empirical studies on persuasion in general - and on the different factors of persuasive messages in particular - have focused almost exclusively on changes in one type of evaluative response, namely self-reported evaluations. While those evaluations are certainly integral to predicting behavior, it is now understood that they are only part of the evaluative picture. Indeed, in the past decade and a half, the importance of a second class of evaluations - which we will call “implicit evaluations” (De Houwer, 2009; De Houwer, Gawronski, \& Barnes-Holmes, in press) has come to the fore. In comparison to explicit evaluations, which are readily accessible and reportable via direct self-report and are generally experienced with a subjective sense of ownership, implicit evaluations are automatically activated, occur relatively outside of consciousness, and do not necessarily include a sense of ownership. It has become clear that implicit evaluations are important because they are related to a wide array of behaviors from addiction (e.g., Wiers \& Stacy, 2006) to consumer behavior (e.g., Maison, Greenwald, \& Bruin, 2004) to social interactions (e.g., Fazio \& Olson, 2003) to voting behavior (e.g., Friese, Smith, Plischke, Bluemke, \& Nosek, 2012). The class of measurement procedures which are generally 
referred to as "implicit measures" is large and growing, with the most prominent examples being the Affective Misattribution Procedure (AMP: Payne, Cheng, Govorun, \& Stewart, 2005), Evaluative Priming (Fazio, Sanbonmatsu, Powell, \& Kardes, 1986), and the Implicit Association Test (IAT: Greenwald, McGhee, \& Schwartz, 1998).

Given the presumed importance of implicit evaluations, researchers have also examined ways to change those evaluations. Indeed, although implicit evaluations were originally assumed to be largely fixed due to their slow accretion over long periods of time, evidence quickly mounted showing a number of ways in which they are malleable (Blair, 2002). Most often, methods for changing implicit evaluations take one of two forms - either (a) training tasks such as picture-picture evaluative conditioning procedures that involve repeated pairings of a target stimuls with other, positive or negative stimuli such as one’s own name, smiling faces, or positive words (e.g., Baccus, Baldwin, \& Packer, 2004; Dijksterhuis, 2004; Hermans, Baeyens, \& Eelen, 2003; Houben, Havermans, \& Wiers, 2010; Phills, Kawakami, Tabi, Nadolny, \& Inzlicht, 2011) or (b) changes to the context in which a stimulus is presented (e.g., Blair, Ma, \& Lenton, 2001; Dasgupta \& Greenwald, 2001; Mitchell, Nosek, \& Banaji, 2003; Wittenbrink, Judd, \& Park, 2001). Examples of the second class of studies are those showing a reduced antiblack bias on a black/white IAT after viewing white individuals on a graffiti-laden street corner and black individuals in a church setting (Wittenbrink et al., 2001) or after presenting people with admired African-Americans and disliked European-Americans (Dasgupta \& Greenwald, 2001).

Recently, however, researchers have also started to explore the impact of direct persuasive information on implicit evaluations. Implicit evaluations have proven remarkably sensitive to the valence of positive or negative written information about a person, consumer 
product, or social group (e.g., De Houwer, 2006; Foroni \& Mayr, 2005; Gregg, Seibt, \& Banaji, 2006; Horcajo, Briñol, \& Petty, 2009; Park, Felix, \& Lee, 2007; Ranganath \& Nosek, 2008;

Ratliff \& Nosek, 2011; Rydell \& McConnell, 2006; Rydell, McConnell, Strain, Claypool, \& Hugenberg, 2007; Smith, De Houwer, \& Nosek, 2013). For example, strong arguments about the health benefits of eating vegetables lead to higher pro-vegetable scores on an IAT as compared to a control condition (Horcajo et al., 2009) and reading a positive message about Arab Muslims leads to a reduction in bias on an IAT as compared to reading a negative message or a neutral message (Park et al., 2007). Clearly, directly presenting verbal information can impact implicit evaluations. This is no longer a question. However, following in the tradition established in persuasion using self-reports, some recent research has also begun to investigate whether the persuasive effectiveness of information changes based on the information's source. Researchers have long known that - at least in most situations - source characteristics (e.g., attractiveness, expertise, trustworthiness) are effective in changing self-reported evaluations (see Briñol \& Petty, 2009 for a recent review). Interestingly, a growing body of research indicates that these source effects also impact persuasion of implicit evaluations.

For example, using an IAT, Forehand and Perkins (2005) found that implicit evaluations of celebrities predicted implicit evaluations of celebrity-endorsed products. Although their study was correlational, it was arguably the first to support the idea that source characteristics of persuasive messages (e.g., the liking of the person who endorses a brand) may impact implicit evaluations. In a more direct test of that concept, IAT scores are more positive toward a political proposal when presented by a member of one's own political party than by another political party (Smith, Ratliff, \& Nosek, 2012). Additionally, responses on an IAT, personalized IAT (Olson \& Fazio, 2004) and AMP were more positive when the source of a persuasive message 
was high in credibility (i.e., expertise and trustworthiness) as compared to low in credibility (Smith et al., 2013).

In the current work, we continue to examine the impact of source factors on implicit evaluations. Previous research on persuasion of explicit evaluations has shown that messages from likeable and attractive sources have more effect than messages from unlikable and unattractive sources (Kahle \& Homer, 1985; Kamins, 1990; Kang \& Herr, 2006; Koernig \& Page, 2002; Messner, Reinhard, \& Sporer, 2008; Reinhard, Messner, \& Sporer, 2006) with some studies on attractiveness supporting a "match-up hypothesis” in which attractive sources are more persuasive than unattractive sources to the extent that the message matches the source, as when an attractive source lobbies for a beauty-related product or service such as a razor, shampoo, or haircut (Kahle \& Homer, 1985; Kamins, 1990; Koernig \& Page, 2002; Parekh \& Kanekar, 1994). Therefore, we investigate for the first time whether sources high in attractiveness (Study 1) and likeability (Study 2) are more impactful on implicit evaluations as indexed by the IAT (Studies 1 and 2) and the AMP (Study 2) than sources low in those characteristics. To be clear, the current work manipulates characteristics of the source and measures the effect of those manipulations on evaluations of a target attitude object presented by the source (e.g., a fictitious product that is described by the source). This is distinct from the focus of prior studies which showed that (a) the attractiveness of a target attitude object (e.g., an unfamiliar person) impacts the implicit evaluation of that target (McConnell, Rydell, Strain, \& Mackie, 2008) or (b) the implicit evaluation of a target attitude is more positive when the target is presented as being similar to the participant (Petty, Tormala, Briñol, \& Jarvis, 2006). Our studies also went beyond previous studies that did examine the impact of source properties on the evaluation of the target object presented by the source. More specifically, our studies 
involved an experimental manipulation of the properties of the source (unlike the correlational study of Forehand \& Perkins, 2005) and directly manipulated the attractiveness or likeability of the source (unlike the studies of Smith et al., 2012, 2013, who manipulated group membership or credibility and did not measure the attractiveness or likeability of the sources).

\section{Study 1 Method}

\section{Participants}

Participants were 269 women who visited the Project Implicit research website. Mean age was 30.1 years $(S D=11.5$; Range $=18-64)$. Participants were restricted to United States citizens of which 74.4\% were White; $10.9 \%$ were African American, 6.4\% were Multiracial; 3.0\% were Asian; and 5.3\% were “Other or Unknown”.

\section{Procedure}

Upon being randomly assigned to this study from the pool of available research studies, participants completed informed consent procedures and were then asked to imagine that they were searching the internet for information about a consumer product named Soltate Facial Soap. They were told that the information they found was at the personal website of a woman named Beth. An image of Beth (either high or low in attractiveness) was presented next to the positive information they read about Soltate Facial Soap. After they read the information about the facial soap, they were asked to report the name of the facial soap and the name of the information's source; data from the 13 (4.8\%) of participants who failed these attentional checks were dropped from the data. Participants then completed the IAT, explicit measures, and measures about the attractiveness, likeability, trustworthiness, expertise, and intelligence of the source. The question about source attractiveness was always the first question they responded to about the source. 
Information About Soltate Facial Soaps. Participants read a short (177-word) passage about Soltate Facial Soaps, titled "Why I like Soltate Facial Soap” (see Appendix A). In this message, the soap was presented as being a very good product.

Attractiveness Manipulation. While reading the information about the product, participants viewed an image of Beth that, as demonstrated in previous research (Vogel, Kutzner, Fiedler, \& Freytag, 2010), was either high or low in attractiveness (Braun, Gründl, Marberger, \& Scherber, 2001).

IAT. Participants completed an IAT with the categories 'Soltate Soaps', 'Other Soaps', 'good', and 'bad'. Stimuli from one of those four categories were presented one at a time on a computer screen. Participants were instructed to categorize the stimuli quickly while making as few errors as possible. Category labels appeared in the upper-left and upper-right of the screen and participants used the "E" and "I" keys to categorize stimuli to the left and right, respectively. Stimuli for the IAT (Appendix B) were the words 'Soltate Soaps' and three liquid soap bottles with the word "Soltate” on them and the words 'Other Soaps' and the same three soap bottles with the word “Other” on them; evaluative stimuli were five good words (e.g., wonderful) and five bad words (e.g., nasty). Construction of the IAT followed recommendations of Nosek and colleagues (Nosek, Greenwald, \& Banaji, 2005; 2007). Participants began with 20 trials sorting 'Soltate Soaps' stimuli to the left and stimuli related to 'Other Soaps' to the right (half the participants completed the IAT this way, while the other began by sorting 'Soltate Soaps' stimuli to the right). They then completed 20 trials sorting positive stimuli to the left and negative stimuli to the right. Next, participants completed 56 trials in which stimuli related to 'Soltate Soaps' and positive shared a single response key while stimuli related to 'Other Soaps' and negative shared a single response key. Participants then spent 40 trials practicing sorting stimuli 
related to 'Soltate Soaps' and 'Other Soaps' with the side of the screen reversed (i.e., participants who had previously been sorting 'Soltate Soaps' stimuli to the left now practiced sorting them to the right). Finally, participants completed a second set of 56 trials in which 'Soltate Soaps' stimuli shared a response key with negative and 'Other Soaps' stimuli shared a response key with positive (or vice versa). If the participant made an error in categorizing, a red " $\mathrm{X}$ " appeared on the screen and the participant corrected their mistake in order to continue. Latencies were recorded until a correct response was made. IAT scores were calculated using the $D$-algorithm (Greenwald, Nosek, \& Banaji, 2003). Trials with reaction times shorter than 400ms or longer than $10000 \mathrm{~ms}$ were removed. Positive scores indicate a preference for Soltate Soaps relative to Other Soaps. IAT scores from 16 participants (6.3\%) were dropped for overall error rates above $30 \%$ or above $40 \%$ for any one block. Cronbach's alpha - calculated using two IAT scores, one from the first 20 trials of each of the critical blocks, and the second from the subsequent 36 trials - for the remaining 240 IATs was $.65^{1}$.

Other measures. Explicit evaluations were measured by asking participants to respond to the following item: "Which of the following statements best describes you?” A 7-point scale was used anchored by “I strongly prefer Soltate Soaps to Other Soaps” (coded as +3) and "I strongly prefer Other Soaps to Soltate Soaps” (coded as -3). Additionally, participants responded to the item "How positive or negative is your attitude toward Soltate Soaps" using a 7-point scale anchored by 1 = "Very negative" and 7 = "Very positive"; these responses were highly related (alpha $=.82)$ and were combined before analyses were conducted. Participants were also asked to report how attractive, likeable, trustworthy, expert, and intelligent they found the source of the information about Soltate Soaps. The responded to each of these five items using a 5-point scale from "Not at all" (coded as 1) to "Very" (coded as 5). 


\section{Results and Discussion}

Overall, participants' showed an implicit preference for 'Soltate Soaps’ relative to 'Other Soaps' $(M=0.57, S D=0.35, t[239]=25.38, p<.0001, d=1.64)$; implicit preferences were not related to explicit preferences, $r=.09, p=.17^{2}$. Our manipulation of source attractiveness was successful; participants rated the source as being more attractive when they were in the 'High Attractiveness' condition $(M=3.84, S D=0.96)$ than the 'Low Attractiveness' condition $(M=$ 2.17, $S D=1.19), t(236)=11.84, p<.0001, d=1.54$. Participants also rated the source as being more likeable when they were in the 'High Attractiveness' condition $(M=4.02, S D=1.01)$ than the 'Low Attractiveness' condition $(M=3.67, S D=1.09), t(236)=2.55, p=.011, d=0.33$. Sources in the 'High Attractiveness' condition did not rate the source as being more expert, intelligent, or trustworthy as compared to the 'Low Attractiveness' condition, all $t$ s $<1.55$, $p$ s $>$ $.12, d \mathrm{~s}<0.20$.

Supporting the central hypothesis, manipulating the level of source attractiveness significantly affected implicit preferences; participants indicated a stronger implicit preference for Soltate when that information was presented by an individual 'High' in attractiveness ( $M=$ $0.63, S D=0.34)$ than 'Low' in attractiveness $(M=0.51, S D=0.35), t(238)=2.53, p=.012, d=$ 0.33. Further, replicating previous research on explicit evaluations, participants reported a greater preference for Soltate when that information was presented by an individual 'High’ in attractiveness $(M=0.24, S D=0.94)$ than 'Low' in attractiveness $(M=-0.01, S D=0.94), t(237)$ $=2.15, p=.033, d=0.28$.

As noted, the sources in the different conditions differed not only in attractiveness but also in likeability. Granted, the effect sizes are noticeably different, with the impact of the source 
manipulation being smaller on reports of likeability than on reports of attractiveness. More importantly, the effect of the source manipulation on IAT scores remained significant when controlling for likeability, $t(235)=2.26, p=.025$, implying that a mediational relationship is not present. This was confirmed via a test of the indirect effect using 1000 bootstrapped samples (Preacher \& Hayes, 2008) which also indicated that ratings of likeability did not statistically mediate the observed effects of the source on implicit evaluations, $\mathrm{CI}_{95 \%}=-.002-.035$. One possible explanation of these results is that the changes in likeability were the result of changes in physical attractiveness (e.g., via the "What is beautiful is good” heuristic; see Dion, Berscheid, \& Walster, 1972). In Study2, we directly manipulated the likeability of the source (Chaiken, 1980). In addition, we investigated whether the impact of source properties can also be found on a second implicit measure, the AMP.

\section{Study 2 Method}

\section{Participants}

Eighty-seven students at Ghent University completed the study for partial completion of a course requirement or for 8 Euro. Mean age of the participants was $19.1(S D=1.95)$ and 63\% were women. One participant was disqualified for having previously participated in a similar study.

\section{Materials}

Likeability Manipulation. Adapted from Chaiken (1980), the manipulation consisted of a fragment of an interview with a professor. In the fragment, the professor is asked whether he enjoys working with students. In the 'Likeable' condition, he replies that he quite enjoys working 
with students and says several nice things about them. In the 'Unlikeable' condition, however, he notes that students are immature and irresponsible and that he dislikes having contact with them.

Information about Comprehensive Exams. Following Petty, Harkins and Williams (1980), the text informs participants about a new exam referred to as "comprehensive exams" designed to test a student's learning during college. The text describes two schools that follow two different plans with regard to comprehensive exams. As such, participants are introduced to the 'Georgia Plan', which incorporates comprehensive exams as part of higher education and the 'Arizona Plan' which does not. The information itself was in favor of the implementation of comprehensive exams, though the arguments were relatively weak (e.g., "These exams have existed since the Ancient Greeks.”).

IAT. The IAT in this study followed the presentation and scoring procedures of Study 1. The categories were ‘Georgia Plan’, ‘Arizona Plan’, 'Positive’, and 'Negative’ (see Appendix B for stimuli). No participants were deleted for error rates being too high; Cronbach's alpha for the IAT was $.54^{3}$.

AMP. In each trial of the AMP, participants see a stimulus followed by a Chinese pictograph. Participants are instructed to ignore the initial "prime” stimulus and rate the pictograph as being more or less pleasant than the average pictograph. We utilized instructions designed to increase participants’ reliance on their “gut-level responses” during the AMP (see De Houwer \& Smith, 2013 for details). The primes were the same stimuli used for the 'Georgia Plan’ and ‘Arizona Plan’ categories in the IAT and a grey rectangle (neutral stimulus). Participants saw 24 of each of the three types of primes, for a total of 72 trials. An individual trial began with the presentation of the prime which was on the screen for $75 \mathrm{~ms}$. This was 
followed by a blank screen for $125 \mathrm{~ms}$ after which one of the 72 Chinese pictographs was presented for 100ms. Finally, a mask image was presented (a black and white image) until the participant made a response. Individual AMP scores were calculated by subtracting the proportion of “pleasant” responses following a “Comprehensive Exams” prime from the proportion of “pleasant” responses following a “Not Comprehensive Exams” prime. Positive AMP score indicated a preference for Comprehensive Exams. A correlation between the first and second block of 36 trials indicated a Cronbach’s alpha of $.44^{4}$.

Other measures. Participants reported explicit evaluations of comprehensive exams by responding to two items; one item indexed the positivity/negativity of their evaluations of comprehensive exams, while the other item indexed their relative preference for comprehensive exams compared to no comprehensive exams. Both items used a 7-point scales ranging from -3 to +3 ; -3 was used to indicate "Extremely negative" and "Strongly prefer no comprehensive exams to comprehensive exams" and +3 was used to indicate "Extremely positive” and “Strongly prefer comprehensive exams to no comprehensive exams”. As these items were highly correlated (Cronbach's alpha $=.93$ ), they were averaged in order to create a single indicator of explicit evaluations. Participants also responded to their perceptions of the source of the message using a 5-point scale ranging from -2 = "Strongly disagree" to $+2=$ "Strongly agree". They did so by signifying agreement with the sentence "I like the writer of the argument text" and two other sentences which included synonyms (in Dutch) in place of the word "like”. Alpha of these three items was .94 , so they were combined into a single scale via averaging.

\section{Procedure}


Participants were first given one of the two types of information about the professor (i.e., 'Likeable' or 'Dislikeable') and were asked to form an impression of him. They were then told that the professor was interested in implementing a new form of exam - called a "comprehensive exam” at the University that the participants attend. They were then given the text of the argument in support of comprehensive exams which was attributed to the professor. After reading the argument, they were asked to name the form of exam. Data from the five participants who did not successfully respond with "comprehensive exam” were dropped from all analyses. Next all participants completed the IAT, AMP, explicit measures, and manipulation checks in that order.

\section{Results and Discussion}

Overall, participants indicated an overall preference for Comprehensive Exams when measured with the IAT ( $M=0.32, S D=0.36), t(86)=8.08, p<.0001, d=0.87$. Participants did not show evidence for an implicit preference when measured using the AMP, $(M=0.02, S D=$ $0.21), t(86)=0.89, p=.38, d=0.10$. Explicit evaluations correlated with the IAT at $r=.52, p<$ .0001 and with the AMP at $r=.15, p=.15$; IAT scores correlated with AMP scores at $r=.31, p$ $=.004^{5}$. Our manipulation of likeability was successful; participants reported liking the professor more in the 'Likeable' condition $(M=0.67, S D=0.63)$ than in the 'Unlikeable' condition $(M=$ $0.61, S D=0.90), t(85)=7.52, p<.0001, d=1.64$.

Confirming our central hypothesis, when responding using the IAT, participants implicitly preferred comprehensive exams more when presented by a 'Likeable' source ( $M=$ $0.44, S D=0.33)$ than by an 'Unlikeable' source $(M=0.21, S D=0.36), t(85)=3.14, p=.002, d$ $=0.68$. In addition, with regard to explicit evaluations, participants reported liking 
comprehensive exams more when presented by a 'Likeable' source $(M=0.43, S D=1.29)$ than by an 'Unlikeable' source $(M=-0.22, S D=1.51), t(85)=2.13, p=.036, d=0.46$.

Data for the AMP were analyzed using a 3 (prime: Comprehensive Exams vs. neutral vs. No Comprehensive Exams) x 2 (condition: Likeable vs. Unlikeable) ANOVA with prime as a within-participants factor and condition a between-participants factor. The key interaction between prime and likeability of the source did not reach significance, $F(2,78)=1.84, p=.17$; evaluations of comprehensive examinations did not indicate more positivity when they were presented by a 'Likeable’ source as compared to an 'Unlikeable’ source. Another way of scoring the AMP is to subtract the proportion of positive responses to Chinese characters following 'Comprehensive Exams’ primes from the proportion of positive responses following 'No Comprehensive Exams’ primes (e.g., De Houwer \& Smith, 2013; Payne et al., 2005). When scored this way, we can see that although participants showed more of a preference for Comprehensive Exams in the 'Likeable' condition $(M=.046, S D=.21)$, than in the 'Unlikeable' condition $(M=-.003, S D=.20)$ this was not a reliable difference, $t(85)=1.10, p=.28, d=0.24$ This lack of a reliable difference stands in contrast to previous work showing that an AMP measuring evaluations of a consumer product was sensitive to the trustworthiness of the source of a persuasive message regarding that product (Smith et al, 2013; Study 4). There are several differences between the two studies which may account for the discrepancy between these two results. The first is that the current study is relatively underpowered. Additionally, the AMP in the current study always appeared after the IAT, and it is possible that the effect of the manipulation was relatively weak at that point in time. Indeed, a reanalysis of the data from Smith et al. (in which the order of measures was counterbalanced) indicates that although there was not a significant order effect, $F(1,428)=0.77, p=.38$, when the AMP was completed first, 
the critical comparison was descriptively larger in size, $d=0.48$ and was highly significant, $t(214)=3.36, p=.0009$, whereas when the AMP was completed following the IAT (as in the current study), the critical comparison was smaller ( $d=0.23)$, and only approached significance, $t(214)=1.65, p=.101$. Thus, it is possible that the likelihood of finding a significant difference on the AMP was reduced in the current study based on its order. In summary, participants' IAT scores and self-reports are more in line with a persuasive message when that message is attributed to a likeable source; AMP scores follow a similar pattern, but non-significantly so.

\section{General Discussion}

In contrast to decades of research on persuasion of explicit evaluations and more than a decade of research on changing implicit evaluations via training tasks or context effects, the present work adds to the growing body of research indicating that implicit evaluations can also be changed through direct persuasive attempts. At this point it is abundantly clear that an individual's performance on implicit measures such as the IAT can be altered. The next step is to systematically test the conditions under which such alterations can and do occur. Such research on persuasion of implicit evaluation is also interesting at the theoretical level. Research on changing implicit evaluations has been strongly influenced by theories within implicit social cognition. These theories share the assumption that implicit measures tap mental associations and, as a result, attempts to change them have either retrained those associations (e.g., by adding new positive associations with an attitude object) or activated a subset of associations through a manipulation of the mental context before or during measurement (see Gawronski \& Bodenhausen, 2011). However, these assumptions may be restrictive when considering potential methods of changing implicit evaluations (see Smith et al., 2013; Whitfield \& Jordan, 2009). 
In considering the current work, we took a broader view of evaluations - and one in which implicit evaluations are not necessarily mediated by associations (De Houwer, 2009; De Houwer et al., in press). Indeed, the current work is equally inspired by theoretical models within persuasion - such as the ELM and HSM - which used explicit self-reports as their dependent variable of interest. The current work builds on previous research showing that implicit evaluations can be impacted by source credibility (Smith et al., 2013), and goes beyond that research by exploring additional variables that moderate persuasion of implicit evaluations. Our results demonstrate for the first time that source variables of attractiveness and likeability previously used to optimize persuasion of explicit evaluations - are also effective in moderating responses on the IAT. Indeed, if anything, the effects were larger on implicit evaluations than on explicit evaluations.

\section{Relationship between implicit and explicit evaluations in the current data}

In both studies, measures of explicit and implicit evaluations of the target object were more positive when the source of the persuasive information was positive (i.e., attractive or likeable). Although this parallel suggests that similar processes might mediate (changes in) explicit and implicit evaluations, it should be noted that the effect of source attractiveness was descriptively larger on implicit measures than on explicit measures. The latter finding resonates with the idea that implicit evaluations are more affect-laden (e.g., Rudman, 2004; Smith \& De Houwer, under review; Smith \& Nosek, 2011) and might thus be impacted more strongly by affect-related variables such as source attractiveness and likeability. However, it is also the case that implicit and explicit evaluations were not correlated in Study 1 which may suggest that the two types of measures change via different processes, at least under some conditions. Our reason for including explicit evaluations was not to directly compare implicit to explicit, but so that we 
had evidence that our manipulation was working as in previous research (e.g., if we did not observe differences using our explicit measure, we would be concerned about the effectiveness of the manipulation). In other words, we were more interested in whether implicit and explicit both showed an effect in the same direction than we were in interpreting potential differences in the size of that effect (which the lack of correlation combined with the significant main effect indicates).

However, recent research (Whitfield \& Jordan, 2009) has argued that in tasks using propositional learning similar to the one we employed, both implicit and explicit evaluations change, with the changes in implicit evaluations mediated by explicit evaluations (though we point out that reverse mediation also held in those studies). Given the similarities between that work and the current work, we note that the effect of the manipulation of attractiveness on IAT scores (Study 1) remains significant when controlling for explicit evaluations, $t(236)=2.37, p=$ .019, while the effect of the manipulation of attractiveness on explicit evaluations becomes nonsignificant when controlling for implicit evaluations, $t(236)=1.95, p=.052$. However, neither the mediational pathway of implicit on explicit $\left(\mathrm{CI}_{95 \%}=-.017-.082\right)$ nor that of explicit on implicit $\left(\mathrm{CI}_{95 \%}=-.005-.026\right)$ shows evidence for mediation. In Study 2, the effect of the manipulation of likeability on IAT scores remains significant when controlling for explicit evaluations, $t(84)=2.33, p=.022$, while the effect of the manipulation of likeability on explicit evaluations becomes non-significant when controlling for implicit evaluations, $t(84)=0.65, p=$ .52. In this case, both the mediational pathways of implicit on explicit $\left(\mathrm{CI}_{95 \%}=.213-.872\right)$ and that of explicit on implicit $\left(\mathrm{CI}_{95 \%}=.023-.159\right)$ show evidence for mediation.

Following Whitfield and Jordan (2009), we would have expected that changes in implicit evaluations would be mediated by changes in explicit evaluations in both studies. However, the 
evidence is, if anything, in support of the idea that implicit and explicit evaluations change in concert; in Study 1, neither was a mediator, while in Study 2 they both mediated each other. Again, the current studies were not designed to test such mediational questions which, while important, likely require significant advances in our understanding of the interplay of implicit and explicit evaluations before they will be tractable.

\section{Implications for models of persuasion of implicit evaluations}

Putting aside the potential differences between implicit and explicit measures, how do the observed source effects operate to influence implicit evaluations? The first possibility can be thought of in terms of a purely associative account. In this account, the attractive or likeable source is more positive than the unattractive or unlikeable source and this extra positivity gets associated with the attitude object (i.e., consumer product or comprehensive exams) leading to a more positive implicit association in the former case as compared to the latter. According to the match-up hypothesis (e.g., Koernig \& Page, 2002) mentioned at the end of the introduction of our paper, explicit evaluations are only impacted by source attractiveness when attractiveness is relevant to the attitude object, implying that explicit evaluations are not always changed through a simple associative mechanism. Based on these considerations, we ran a direct replication of Study 1 in which we changed the attitude object to Soltate Laundry Detergents (see Smith et al., 2013) for which the attractiveness of the source is likely much less relevant than for Soltate Facial Soaps. In this case, evaluations were not impacted by the attractiveness of the source. Specifically, participants did not show a greater implicit preference for Soltate Laundry Detergents (using an IAT) when persuasive information was presented by an individual 'High' in attractiveness as compared to 'Low' in attractiveness, $t(287)=0.69, p=.49, d=0.08$. As such, this is the first (albeit preliminary) indication that the "match-up hypothesis" may also hold for 
implicit evaluations. In addition, the data provided additional support for the match-up hypothesis regarding explicit evaluations in that no difference was found for explicit preference for Soltate Laundry Detergents based on the attractiveness of the source, $t(296)=0.62, p=.53, d$ $=0.07$. Although strong conclusions must await the results of an additional study in which the nature of the attitude object is manipulated, the between-experiment observation that the positivity of the source only impacts implicit evaluations when the source characteristic is relevant to the persuasive message argues against a purely associative account of changing implicit evaluations.

Another possibility is that an attractive or likeable source could signal that the information is more important than an unattractive or unlikeable source does and, therefore, the valence of the persuasive information should be given increased weight. This is, in general, what is observed for explicit evaluations, where source variables such as expertise bias the amount of thinking that occurs during the persuasive attempt, leading to more change in response to positive sources with positive messages (see Petty \& Briñol, 2008 for a review). For instance, the information about comprehensive exams in Study 2 may have led to more positive pro-exam IAT scores because participants weighted it more heavily while reading it when it was presented by a likeable source. One way to compare this account with a simple associative account would be to vary whether the information about the source is presented before or after the persuasive message (as in e.g., Tormala et al., 2007). Notably, all previous studies of source effects on implicit evaluations have placed the source information before the persuasive message.

A third possibility is that source effects impact implicit evaluations through an additive process by which a given IAT score is the result of the combination of the positive and negative arguments contained within the persuasive argument and the information about the argument's 
source (see Kruglanski \& Thompson, 1999 with relation to explicit evaluations). In the context of the current work, the positive information about Soltate Facial Soaps was held constant, while the attractive source was an additional piece of positive information in favor of Soltate Facial Soaps and the unattractive source was not (and may have subtracted from the positivity of the evaluation). Interestingly this account would predict that, if the persuasive information about Soltate Facial Soaps was negatively-valenced (i.e., a negative review of the product), then implicit evaluations would be less negative when the source was attractive than when they were unattractive, because the positivity of the attractive source would partially counter the negative valence of the persuasive message. Such investigations have yet to be undertaken regarding implicit evaluations, but are certainly intriguing. It is also unclear how this simple additive account would explain the "match-up" results (i.e., no effect of source attractiveness unless attractiveness is relevant for evaluations of the attitude object), unless by positing a two-stage system in which the additive process comes online only when there is a match between the source's attractiveness and the attitude object.

Finally, a propositional account can also be put forward (see De Houwer, 2009; Hughes, Barnes-Holmes, \& De Houwer, 2011). When presented with an attractive source presenting a persuasive message about beauty products, participants might form a proposition such as "beauty products recommended by attractive people are good, hence this product must be good" while participants seeing the same message from an unattractive source may form a proposition such as "beauty products recommended by unattractive people may not be good, hence this product might not be good". The differences in these propositions, then, would be mirrored in the observed differences in IAT scores.

\section{Limitations of the current data}


One important limitation of the present results is that the effects of source variables were observed only when the IAT was used as an index of implicit evaluation. In Experiment 2, we did use the AMP in addition to the IAT and, while observed effects on the AMP were in the predicted direction, they did not reach significance. As we argued in the discussion section of that experiment, it is possible that the lack of effects on the AMP was related to the fact that the IAT always came before the AMP. As such, by the time that participants completed the AMP, the effects of the persuasive message might have dissipated. Even though the IAT is currently the most widely used and reliable index of implicit evaluation, it would be preferable if the present results could be replicated with other indices. Alternately, one could apply multinomial models and techniques to try to improve inferences about the nature of the processes underlying task performance. For instance, it would be interesting to examine which parameters of the multinomial QUAD model would be affected by persuasive messages (see Calanchini \& Sherman, 2013, for an excellent review of evidence showing that performance and processes need to be separated).

An additional concern is that the current results could be due to participants complying with perceived demand characteristics, especially since previous research shows that novel attitudes can be "faked" on the IAT (De Houwer, Beckers, \& Moors, 2007). However, in the current work, participants were exposed to only one of the levels of the independent variable (e.g., either to attractive and likeable or to the unattractive and unlikeable source), so this is only a modest concern unless they were still able to somehow intuit the study's impetus. In addition, Study 1 was conducted over the internet (with high anonymity and no researcher present) which should decrease concerns about demand effects. Further, although IAT scores - and, for that matter, other implicit measures - may be susceptible to demand effects, scores on the IAT are 
almost certainly less susceptible to such effects than are explicit self-reports. The fact that, in both studies, the impact of the source on evaluations was descriptively larger on implicit measures than on explicit measures either indicates that one need worry about demand effects in all persuasion research - even when such research is conducted between-participants - or lessens our concern that demand effects are driving the observed effects on the IAT.

\section{Future directions}

Despite its limitations, the present research provides a step forward in a promising new line of research that could lead to both effective and efficient ways of changing implicit evaluations and, in that way, behavior. If implicit evaluations do contribute in a unique manner to behavior, ways to change implicit evaluations can also help change behavior in unique ways. Until now, researchers have primarily attempted to change implicit evaluations through context effects or by using procedures that involve extensive training (e.g., repeatedly approaching or avoiding a stimulus; e.g., Phills et al., 2011). Data such as ours suggest that verbal messages could provide a more efficient way of changing implicit evaluations. However, it still remains to be established whether this type of persuasion is as effective in changing implicit evaluations as are training procedures. Indeed, the effects of persuasion and training need to be compared on a number of variables. To date, very little research has examined the longevity of the impact of direct persuasive attempts on implicit evaluations (see Ranganath \& Nosek, 2008; Smith et al, 2012). Note, however, that there is also very little evidence on the longevity of the effects of training (but see Wiers, Eberl, Rinck, Becker, \& Lindenmeyer, 2011, for a study on the long term effects of approach-avoid training on relapse in addicts). Second, there is also little information on whether persuasion can change well-established implicit evaluations. In most of the relevant studies, including the present one, novel attitude objects were used. It might well be that 
persuasion is more effective in establishing novel implicit evaluations than in changing older ones. As such, it should be illuminating to compare the effectiveness of persuasion and training in a variety of contexts that differ with regard to the nature of the attitude object. Third, the fact that verbal messages that are processed consciously can lead to changes in implicit evaluations at least raises the possibility that the effects of training procedures might be mediated by conscious knowledge (see Hofmann, De Houwer, Perugini, Baeyens, \& Crombez, 2010, for a recent review of the evidence regarding the role of conscious knowledge in evaluative conditioning training tasks). Notably, source effects were absent in Smith et al (2013) when participants’ ability to think was restricted by a cognitive load manipulation, and it might well be that training procedures have an effect only if participants become aware of the contingencies on which the training is based (e.g, "approach this object and avoid another object”; but see Kawakami, Phills, Steele, \& Dovidio, 2007, for evidence suggesting that approach-avoid training has an effect also when stimuli are presented subliminally).

\section{Conclusion}

The current studies contribute to emerging evidence that implicit evaluations can be changed via direct persuasive messages and, most critically, that the source of the information plays a role in the effectiveness of the persuasive attempt. IAT scores (but not AMP scores), were more in line with the positive content of the persuasive message when the source of the message was attractive (Study 1) and likeable (Study 2). Notably, observed effects were rather small in Study 1 and, when larger (in Study 2), may not have been long-lasting (as one explanation for the null effects using the AMP is that the effect of the source disappeared during the time it took to complete the IAT). As such, our results confirm that verbal persuasive messages can change implicit evaluations and implicate two new aspects of the message's source 
that facilitate such changes. Given that the effects are rather small, future research could shed light on how these effects can be optimized. 


\section{Footnotes}

${ }^{1}$ We follow the recommendation of Lebel and Paunonen (2011) in also reporting the reliability estimates separately by condition. In the 'High Attractiveness' condition, alpha was .69, whereas in the 'Low Attractiveness' condition alpha was .59; this did not constitute a significant difference $(W=0.76, p=.064)$.

${ }^{2}$ Additionally, implicit and explicit evaluations were not significantly related in either the 'High Attractiveness' condition ( $r=.11, p=.23$ ) or the 'Low Attractiveness' condition ( $r=.03, p=$ $.75)$; these two correlations did not differ from one another $(z=0.62, p=.54)$.

${ }^{3}$ In the 'Likeable' condition, alpha for the IAT was .47, whereas in the 'Unlikeable' condition alpha was .53); this did not constitute a significant difference $(z=0.82, p=.79)$.

${ }^{4}$ In the 'Likeable' condition, alpha for the AMP was .51, whereas in the 'Unlikeable' condition alpha was .38); this did not constitute a significant difference $(z=0.51, p=.70)$.

${ }^{5}$ None of these relationships differed by experimental condition (all zs $<1.56$, ps $>.12$ ). 


\section{References}

Baccus, J. R., Baldwin, M. W., \& Packer, D. J. (2004). Increasing implicit self-esteem through classical conditioning. Psychological Science, 15, 498-502.

Blair, I. V. (2002). The malleability of automatic stereotypes and prejudice. Personality and Social Psychology Review, 6, 242-261.

Blair, I. V., Ma, J. E., \& Lenton, A. P. (2001). Imagining stereotypes away: The moderation of implicit stereotypes through mental imagery. Journal of Personality and Social Psychology, 81, 828-841.

Braun, C., Grundl, M., Marberger, C., \& Scherber, C. (2001). Beautycheck: Ursachen und folgen von attraktivat [Beautycheck: Causes and consequences of attractiveness]. Retrieved from http://www.uniregensburg.de/Fakultaeten/phil_Fak_II/Psychologie/Psy_II/beautycheck/english/bericht/b ericht.htm.

Briñol, P., \& Petty, R. E. (2009). Source factors in persuasion: A self-validation approach. European Review of Social Psychology, 20, 49-96.

Cacioppo, J. T., Petty, R. E., \& Morris, K. J. (1983). Effects of need for cognition on message evaluation, recall, and persuasion. Journal of Personality and Social Psychology, 45, 805-818.

Calanchini, J., \& Sherman, J. W. (2013). Implicit attitudes reflect associative, non-associative, and non-attitudinal processes. Social and Personality Psychology Compass, 7, 654-667. 
Chaiken, S. (1980). Heuristic versus systematic information processing and the use of source versus message cues in persuasion. Journal of Personality and Social Psychology, 39, $752-766$.

Fazio, R. H., Sanbonmatsu, D. M., Powell, M. C., \& Kardes, F. R. (1986). On the automatic activation of attitudes. Journal of Personality and Social Psychology, 50, 229-238.

Dasgupta, N., \& Greenwald, A. G. (2001). On the malleability of automatic attitudes: Combating automatic prejudice with images of admired and disliked individuals. Journal of Personality and Social Psychology, 81, 800-814.

De Houwer, J. (2006). What are implicit measures and why are we using them. In R. W. Wiers \& A. W. Stacy (Eds.), The handbook of implicit cognition and addiction (pp. 1128). Thousand Oaks, CA: Sage Publishers.

De Houwer, J. (2009). How do people evaluate objects? A brief review. Social and Personality Psychology Compass, 3, 36-48.

De Houwer, J., Gawronski, B., \& Barnes-Holmes, D. (in press). A functional-cognitive framework for attitude research. European Review of Social Psychology.

De Houwer, J., \& Smith, C. T. (2013). Go with your gut! Effects in the Affect Misattribution Procedure become stronger when participants are encouraged to rely on their gut feelings. Social Psychology, 44, 299-302.

Dijksterhuis, A. (2004). I like myself but I don’t know why: Enhancing implicit self-esteem by subliminal evaluative conditioning. Journal of Personality and Social Psychology, 86, $345-355$.

Dion, K., Berscheid, E., \& Walster, E. (1972). What is beautiful is good. Journal of Personality and Social Psychology, 24, 285-290. 
Fazio, R. H., \& Olson, M. A. (2003). Implicit measures in social cognition research: Their meaning and use. Annual Review of Psychology, 54, 297-327.

Forehand, M. R., \& Perkins, A. (2005). Implicit assimilation and explicit contrast: A set/reset model of response to celebrity voice-overs. Journal of Consumer Research, 32, 435-441.

Foroni, F., \& Mayr, U. (2005). The power of a story: New, automatic associations from a single reading on a short scenario. Psychonomic Bulletin and Review, 12, 139-144.

Friese, M., Smith, C. T., Plischke, T., Bluemke, M., \& Nosek, B. A. (2012). Do implicit attitudes predict voting behavior for undecided voters? PLOS ONE, 7, e44130. doi: 10.1371/jounal.pone.0044130.

Gawronski, B., \& Bodenhausen, G. V. (2006). Associate and propositional processes in evaluation: An integrative review of implicit and explicit attitude change. Psychological Bulletin, 132, 692-731.

Gawronski, B., \& Bodenhausen, G. V. (2011). The associative-propositional model: Theory, evidence, and open questions. Advances in Experimental Social Psychology, 44, 59-127.

Greenwald, A. G., McGhee, D. E., \& Schwartz, J. L. K. (1998). Measuring individual differences in implicit cognition: The Implicit Association Test. Journal of Personality and Social Psychology, 74, 1464-1480.

Greenwald, A. G., Nosek, B. A., \& Banaji, M. R. (2003). Understanding and using the Implicit Association Test: I. An improved scoring algorithm. Journal of Personality and Social Psychology, 85, 197-216.

Gregg, A. P., Seibt, B., \& Banaji, M. R. (2006). Easier done than undone: Asymmetry in the malleability of implicit preferences. Journal of Personality and Social Psychology, 90, 120. 
Hermans, D., Baeyens, F., \& Eelen, P. (2003). On the acquisition and activation of evaluative information in memory: The study of evaluative learning and affective priming combined. In J. Musch \& K. C. Klauer (Eds.), The psychology of evaluation: Affective processes in cognition and emotion (pp. 11-28). Mahway, NJ: Lawrence Erlbaum.

Hofmann, W., De Houwer, J., Perugini, M., Baeyens, F., \& Crombez, G. (2010). Evaluative conditioning in humans: A meta-analysis. Psychological Bulletin, 136, 390-421.

Horcajo, J., Briñol, P., \& Petty, R. E. (2010). Consumer persuasion: Indirect change and implicit balance. Psychology and Marketing, 27, 938-963.

Houben, K., Havermans, R. C., \& Wiers, R. W. (2010). Learning to dislike alcohol: Conditioning negative implicit attitudes toward alcohol and its effect on drinking behavior. Psychopharmacology, 211, 79-86.

Hovland, C. I., Janis, I. L., \& Kelley, J. J. (1953). Communication and persuasion: Psychological studies of opinion change. New Haven: Yale University Press.

Hughes, S., Barnes-Holmes, D., \& De Houwer, J. (2011). The dominance of associative theorising in implicit attitude research: Propositional and behavioral alternatives. The Psychological Record, 61, 465-498.

Kahle, L. R., \& Homer, P. M. (1985). Physical attractiveness of the celebrity endorser: A social adaptation perspective. Journal of Consumer Research, 11, 954-961.

Kamins, M. A. (1990). An investigation into the 'match-up' hypothesis in celebrity advertising: When beauty may be only skin deep. Journal of Advertising, 19, 4-13.

Kang, Y., \& Herr, P. M. (2006). Beauty and the beholder: Toward and integrative model of communication source effects. Journal of Consumer Research, 33, 123-130. 
Kawakami, K., Phills, C. E., Steele, J. R., \& Dovidio, J. F. (2007). (Close) distance makes the heart grow fonder: Improving implicit racial attitudes and interracial interactions through approach behaviors. Journal of Personality and Social Psychology, 92, 957-971.

Koernig, S. K., \& Page, A. L. (2002). What if your dentist looked like Tom Cruise? Applying the match-up hypothesis to a service encounter. Psychology \& Marketing, 19, 91-110.

Kruglanksi, A. W., \& Thompson, E. P. (1999). Persuasion by a single route: A view from the unimodel. Psychological Inquiry, 10, 83-109.

LeBel, E. P., \& Paunonen, S. V. (2011). Sexy but often unreliable: Impact of unreliability on the replicability of experimental findings involving implicit measures. Personality and Social Psychology Bulletin, 37, 570-583.

Maison, D., Greenwald, A. G., \& Bruin, R. H. (2004). Predictive validity of the Implicit Association Test in studies of brands, consumer attitudes, and behavior. Journal of Consumer Psychology, 14, 405-415.

McConnell, A. R., Rydell, R. J., Strain, L. M., \& Mackie, D. M. (2008). Forming implicit and explicit attitudes toward individuals: Social group association cues. Journal of Personality and Social Psychology, 94, 792-807.

Messner, M., Reinhard, M-A., \& Reinhold, S. L. (2008). Compliance through direct persuasive appeals: The moderating role of communicator's attractiveness in interpersonal persuasion. Social Influence, 3, 67-83.

Mitchell, J. P., Nosek, B. A., \& Banaji, M. R. (2003). Contextual variations in implicit evaluation. Journal of Experimental Psychology: General, 132, 455-469. 
Nosek, B. A., Greenwald, A. G., \& Banaji, M. R. (2005). Understanding and using the Implicit Association Test: II. Method variables and construct validity. Personality and Social Psychology Bulletin, 31, 166-180.

Nosek, B. A., Greenwald, A. G., \& Banaji, M. R. (2007). The Implicit Association Test at age 7: A methodological and conceptual revuew. In J. A. Bargh (Ed.), Social Psychology and the Unconscious: The Automaticity of Higher Mental Processes (pp. 265-292). New York: Psychology Press.

Olson, M. A., \& Fazio, R. H. (2004). Reducing the influence of extrapersonal associations on the Implicit Association Test: Personalizing the IAT. Journal of Personality and Social Psychology, 86, 653-667.

Parekh, H., \& Kanekar, S. (1994). The physical attractiveness stereotype in a consumer-related situation. The Journal of Social Psychology, 134, 297-300.

Park, J., Felix, K., \& Lee, G. (2007). Implicit attitudes toward Arab-Muslims and the moderating effects of social information. Basic and Applied Social Psychology, 29, 35-45.

Payne, B. K., Cheng, C. M., Govorun, O., \& Stewart, B. D. (2005). An inkblot for attitudes: Affect misattribution as implicit measurement. Journal of Personality and Social Psychology, 89, 277-293.

Petty, R. E., \& Briñol, P. (2008). Persuasion: From single to multiple to metacognitive processes. Perspectives on Psychological Science, 3, 137-147.

Petty, R. E., \& Cacioppo, J. T. (1986). The elaboration likelihood model of persuasion. In L. Berkowitz (Ed.), Advances in experimental social psychology (vol. 19, pp. 123-205). San Diego, CA: Academic Press. 
Petty, R. E., Harkins, S. G., \& Williams, K. D. (1980). The effects of group diffusion of cognitive effort on attitudes: An information-processing view. Journal of Personality and Social Psychology, 38, 81-92.

Petty, R. E., Tormala, Z. L., Briñol, P., \& Jarvis, W. B. G. (2006). Implicit ambivalence from attitude change: An exploration of the PAST model. Journal of Personality and Social Psychology, 90, 21-41.

Phills, C. E., Kawakami, K., Tabi, E., Nadolny, D., \& Inzlicht, M. (2011). Mind the gap: Increasing associations between the self and blacks with approach behaviors. Journal of Personality and Social Psychology, 100, 197-210.

Preacher, K. J., \& Hayes, A. F. (2008). Asymptotic and resampling strategies for assessing and comparing indirect effects in multiple mediator models. Behavior Research Methods, 40, 879-891.

Ranganath, K. A., \& Nosek, B. A. (2008). Implicit attitude generalization occurs immediately, explicit attitude generalization takes time. Psychological Science, 19, 249-254.

Ratliff, K. A., \& Nosek, B. A. (2011). Negativity and outgroup biases in attitude formation and transfer. Personality and Social Psychology Bulletin, 37, 1692-1703.

Reinhard, M-A., Messner, M., \& Sporer, S. L. (2006). Explicit persuasive intent and its impact on success at persuasion - The determining roles of attractiveness and likeableness. Journal of Consumer Psychology, 16, 249-259.

Rudman, L. A. (2004). Sources of implicit attitudes. Current Directions in Psychological Science, 13, 79-82. 
Rydell, R. J., \& McConnell, A. R. (2006). Understanding implicit and explicit attitude change: A systems of reasoning analysis. Journal of Personality and Social Psychology, 91, 995 1008.

Rydell, R. J., McConnell, A. R., Strain, L. M., Claypool, H. M., \& Hugenberg, K. (2007). Implicit and explicit attitudes respond differently to increasing amounts of counterattitudinal information. European Journal of Social Psychology, 37, 867-878.

Smith, C. T., \& De Houwer, J. (2013). Feel like quitting? Comparing the impact of affective and cognitive persuasive messages on implicit evaluations of smoking. Unpublished manuscript under review.

Smith, C. T., De Houwer, J., \& Nosek, B. A. (2013). Consider the source: Persuasion of implicit evaluations is moderated by source credibility. Personality and Social Psychology Bulletin, 39, 193-205.

Smith, C. T., \& Nosek, B. A. (2011). Affective focus increases the concordance between implicit and explicit attitudes. Social Psychology, 42, 300-313.

Smith, C.T., Ratliff, K. A., \& Nosek, B. A. (2012). Rapid assimilation: Automatically integrating new information with existing beliefs. Social Cognition, 30, 199-219.

Tormala, Z. L., Briñol, P., \& Petty, R. E. (2007). Multiple roles for source credibility under high elaboration: It's all in the timing. Social Cognition, 25, 536-552.

Vogel, T., Kutzner, F., Fiedler, K., \& Freytag, P. (2010). Exploiting attractiveness in persuasion: Senders' implicit theories about receivers’ processing motivation. Personality and Social Psychology Bulletin, 36, 830-842.

Whitfield, M., \& Jordan, C. H. (2009). Mutual influences of implicit and explicit attitudes. Journal of Experimental Social Psychology, 45, 748-759. 
Wiers, R. W., \& Stacey, A. W. (2006). Implicit cognition and addiction. Current Directions in Psychological Science, 15, 292-296.

Wiers, R. W., Eberl, C., Rinck, M., Becker, E. S., \& Lindenmeyer, J. (2011). Retraining automatic action tendencies changes alcoholic patients’ approach bias for alcohol and improves treatment outcome. Psychological Science, 22, 490-497.

Wittenbrink, B., Judd, C. M., \& Park, B. (2001). Spontaneous prejudice in context: Variability in automatically activated attitudes. Journal of Personality and Social Psychology, 81, 815827. 


\section{Appendix A}

\section{Why I like Soltate Facial Soap}

The line of facial cleansers made by SOLTATE has recently become one of my very favorites. Although I use several of their products, the one I really can't do without is SOLTATE Facial Soap. First of all, SOLTATE Facial Soap makes my face feel amazingly clean, fresh, and soft. Even better, that feeling lasts throughout my entire workday! Even now, after months of using this soap, I keep being surprised at how good my face feels at the end of the day. I also like how SOLTATE Facial Soap is made. For example, they start with natural spring water and mix in fruit juices and herbal extracts before adding the active ingredients. And SOLTATE doesn't test their soaps on animals, which is important to me. One of the fun parts about my website is finding out whether other people agree with my reviews. So far, my positive review of SOLTATE has gotten more than $90 \%$ agreement! I would definitely recommend that you try SOLTATE Facial Soap as soon as you can! 


\section{Appendix B}

\section{IAT Stimuli}

\section{Study 1}

Good: Glorious, Marvelous, Peace, Success, Wonderful

Bad: Agony, Evil, Failure, Nasty, Unpleasant

\section{Soltate Soaps:}
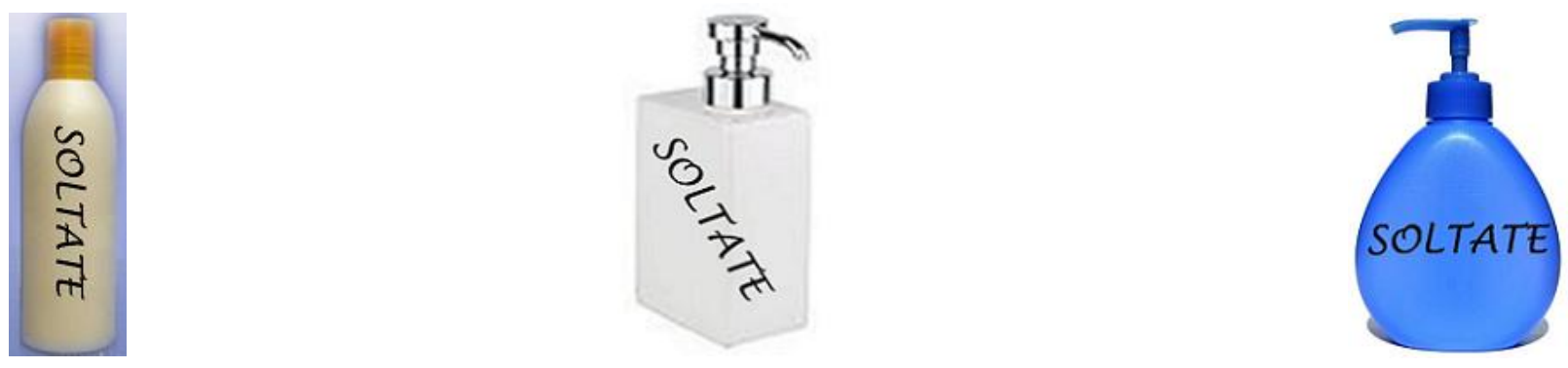

\section{Other Soaps:}
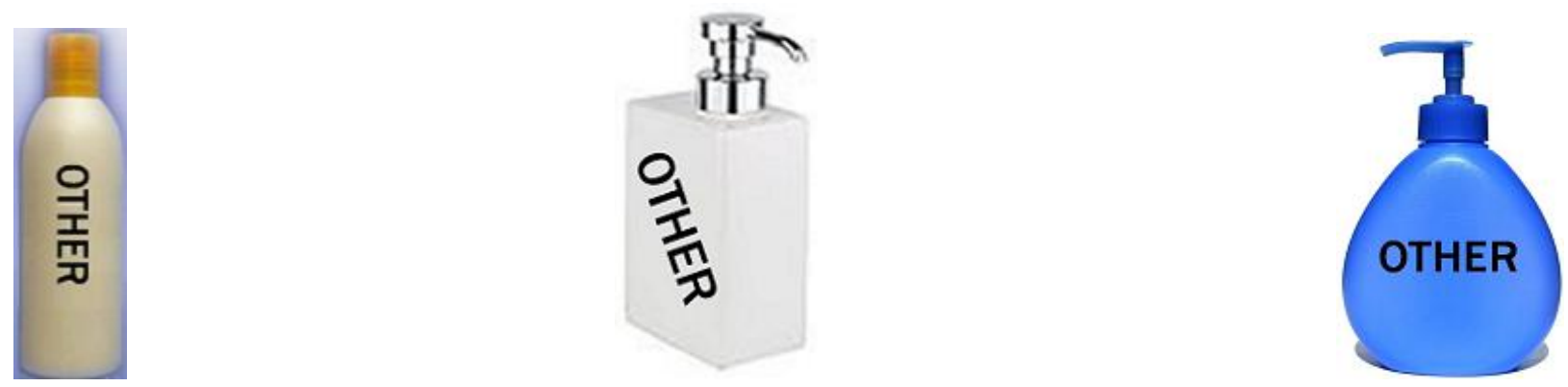

\section{Study 2}

Good: good, happy, honest, outgoing, positive, pleasant, nice, friendly

Bad: false, angry, cruel, jealous, negative, annoying, hateful, unpleasant

Georgia Plan: University of Georgia, Georgia, Comprehensive

Arizona Plan: University of Arizona, Arizona, Not Comprehensive 